\title{
Conducting research about sensitive subjects: The case of homeless youth
}

\author{
Dirigiendo la investigación acerca de asuntos sensibles: \\ el caso de la juventud sin casa ni hogar
}

Enviado: enero 2 de 2010 | Revisado: junio 22 de 2010 | Aceptado: julio 7 de 2011

\author{
Silvia Helena KolleR * \\ Universidade Federal do Rio Grande do Sul, \\ Porto Alegre, Brazil \\ MARCELA RAFFAELLI** \\ University of Illinois, Urbana-Champaign, United States \\ Gustavo CARLO*** \\ University of Missouri, Columbia, United States
}

SICI: 2011-2777(201203)11:1<55:CRSSHY>2.0.CO;2-G

Para citar este artículo: Koller. S. H., Raffaelli, M. \& Carlo, G. (2012). Conducting research about sensitive subjects: The case of homeless youth. Universitas Psychologica, 11(1), 55-65.

* Full professor and chair of the Center for Psychological Studies on At Risk Children, Youth and Families in the Department of Psychology at the Universidade Federal do Rio Grande do Sul, Porto Alegre, Brazil. E-mail silvia.koller@pq.cnpq.br. ResearcherID: Koller, S., B-2629-2008

** University of Illinois, Urbana-Champaign, USA. E-mail:mraffael@uiuc.edu

**** Millsap Professor of Diversity and Multicultural Studies. Department of Human Development and Family Studies, University of Missouri, Columbia, MO 65202, USA. E-mail: carlog@missouri.edu

\begin{abstract}
A B S T R A C T
There is growing interest and importance in addressing the logistical and ethical challenges of conducting research with disenfranchised populations, including homeless and working street youth. Drawing upon established international standards on human rights, we review legal and ethical codes for research on disenfranchised populations established by national and international research and professional organizations. Then we explore how university-based researchers can apply these standards to children and adolescents growing up in situations characterized by physical and psychological neglect, lack of adult supervision, limited protection from local law enforcement, and drug use and violence. We reflect upon on our experiences in conducting research with vulnerable Brazilian youth to illustrate the challenges of implementing ethical guidelines in real-world situations and propose possible solutions to ethical dilemmas encountered in the field. Key words author:

Homeless, ethical issues, youth.

Key words plus:

Risk and protective factors, resilience, culture.
\end{abstract}

\section{RES UMEN}

Hay interés creciente e importancia en los desafíos logísticos y éticos de la dirección de una investigación con poblaciones en situación de vulnerabilidad, incluso los denominados sin hogar y la juventud callejera. Utilizando las normas internacionales establecidas en los derechos humanos, para esta investigación, se retomaron los códigos legales y éticos en estas poblaciones establecidas por organizaciones profesionales y de investigación nacional e internacional. Nosotros exploramos cómo los investigadores basados en las universidades pueden aplicar estas normas a los niños y adolescentes que crecen en las situaciones caracterizados por el abandono físico y psicológico, falta de vigilancia adulta, protección limitada de la ley local, uso de droga y violencia. Nosotros reflejamos en nuestras experiencias, dirigiendo la investigación con la juventud brasileña vulnerable, para ilustrar los desafíos de llevar a cabo las pautas éticas en las situaciones del mundo real y proponer las posibles soluciones a los dilemas éticos encontrados en el campo.

Palabras clave autor:

Niños de la calle, ética, jóvenes.

Palabras clave descriptores:

Factores de riesgo y de protección, resiliencia, cultura. 
Research conducted with vulnerable subject groups, such as homeless and impoverished populations, demands heightened attention to ensuring that the rights of participants are protected. In this paper, we consider the ethical implications of conducting research with homeless and impoverished youth and discuss some typical ethical dilemmas encountered by researchers. Although we draw on our experiences in Brazil, the issues encountered are similar to those encountered in research with disenfranchised populations around the world.

Traditional disciplinary guidelines and codes are often insufficient to address the ethical dilemmas that emerge when conducting research with vulnerable populations. Those codes are usually based on universal and immutable rules that are organized according to the ethical principles of respect for persons, privacy, justice, beneficence, and nonmaleficence (Fontes, 1998). However, when conducting research with children and adolescents in situations of vulnerability (e.g., those who have experienced sex exploitation, used drugs, are perpetrators or victims of domestic violence, or juvenile offenders), the ethical issues become magnified. The complexities are further accentuated because issues of autonomy, informed consent, confidentiality, and protecting participants' safety and wellbeing need to be at the forefront when planning research (Yick, 2007). This paper examines some ethical issues in research with sensitive populations, with a focus on investigations of sexuality, drug use, and family violence. It suggests ways for researchers to increase understanding, apply ethical guidelines appropriately, guarantee their own protection, and avoid abuses of power. Special attention is given to methodological issues related to ethics, due to their complexity and importance for science.

\section{Children's and Adolescents' Rights}

A variety of mechanisms are in place for protecting the rights of children and adolescents in research settings. Existing mechanisms include international treaties, national laws, and ethics codes of professional organizations. The international community has long recognized the importance of protect- ing the rights and privileges of youth. The United Nations Convention on the Rights of the Child (UNCRC; United Nations, 1989) has been ratified by all but two of the member nations of the U.N. (the United States and Somalia). The document states in the Preamble that "the United Nations has proclaimed that childhood is entitled to special care and assistance" and recalls that this privilege was previously recognized in U.N. documents such as the 1924 Geneva Declaration of the Rights of the Child, the 1948 Universal Declaration of Human Rights, the 1959 Declaration of the Rights of the Child, and the 1966 International Covenant on Civil and Political Rights. The UNCRC specifically addresses the need to protect the harmonious development of the child and explicitly acknowledges the best interests of the child, the rights of youth to participate in decisions that concern them, and the right to "freedom of expression; this right shall include the freedom to seek, receive, and impart information...either orally, in writing or in print" (p. 5). To protect these and other rights the States Parties can "encourage the development of appropriate guidelines for the protection of the child from information and material injurious to his or her well-being" (p. 6). These proclamations set the international standards and parameters for the ethical treatment of youth in all activities including research.

At the national level, many countries have laws that govern research activities to ensure the ethical treatment of youth. For example, in the United States, federal laws regulate the behavior of researchers; research involving children is governed by 45 CFR 46:401-409 (48 Fed. Reg. 9818, March 8, 1993). A variety of mechanisms exist for ensuring that the rights of research participants are observed (see also Collaborative Institutional Training Initiative [CITI] and the University of Miami online ethics program, Health Information Privacy and Security [HIPS]; www.citiprogram. org). Mechanisms typically include the need for University-based researchers to obtain approval from an Institutional Review Board (IRB), which are typically granted authority to review and ensure safe practices in research involving human beings. 
In most cases, youth may participate in research only with approval from parent(s) or a legal guardian; exceptions are made if youth are considered emancipated or a waiver of parental consent is granted. Investigators must also solicit the assent of children aged 7 years or older.

In addition to these federal laws regulating research with children and adolescents, professional organizations in the U.S. (e.g., American Psychological Association, Society for Research in Child Development, Society for Research on Adolescence) have developed ethical standards governing how members should conduct research. For example, the Society for Research in Child Development (SRCD), the largest professional psychological child research organization, has established a set of Ethical Standards for Research with Children. The SRCD research policy provides strict guidelines that endorse non-harmful procedures, requires informed consent from parents, youths, and other research participants (e.g., school teachers), promotes the fair use of incentives, bars the use of unnecessary deception, preserves anonymity and confidentiality of research participants, and ensures the safe and responsible treatment of participants during research procedures. There are guidelines for handling scientific misconduct and enforcing any consequences (e.g., expulsion from the society) that stem from a violation of the standards. Professional organizations at the national and international level around the world typically develop similar guidelines to help scholars conduct ethical research.

These laws and ethical standards provide useful guidelines for scholars who are engaged in research and practice with youth. However, scholars who work in settings that are outside those typically encountered by mainstream researchers (e.g., schools, homes, or other adult-supervised contexts) often face unique situations that make it difficult to comply with standard ethical guidelines or that challenge the sufficiency of existing guidelines. One population that raises unique considerations consists of "street youth", defined by the United Nations as "any boy or girl ... for whom the street (in the widest sense of the word, including unoccupied dwellings, wasteland, etc.) has become his or her habitual abode and/or source of livelihood; and who is inadequately protected, supervised, or directed by responsible adults" (quoted in Lusk, 1992, p. 294). Unsupervised children and adolescents can be found on the streets of most large cities around the world, begging for food or money, engaging in "street work" (e.g., selling candy, shining shoes), or just hanging around (Neiva-Silva \& Koller, 2002).

Youth living in contexts of homelessness and impoverishment pose unique social welfare, human rights, and policy challenges to the societies in which they are found (Koller \& Raffaelli, 2001). In addition, researchers and practitioners who work with street youth must confront an array of methodological and ethical considerations (Carvalho et al., 2006; Hutz \& Koller, 1999; Neiva-Silva, Lisboa, $\&$ Koller, 2005). Yet, despite the dramatic increase in research on street youth in the last decades, little published literature focusing on the ethical considerations raised by such research exists. As a result, researchers have little information on which to draw. Drawing on our experiences in Brazil, we consider some of the ethical implications of conducting research with impoverished and homeless children and adolescents. Our paper is divided into two main sections. The first briefly describes the historical, economic, and legal context in Brazil, and delineate the steps that federal and local governments have taken to protect the rights of children and adolescents. The second section draws on our research experiences to identify ethical issues we have encountered and discusses ways we have addressed those issues.

\section{The Brazilian Context}

The current situation of Brazilian street youth must be understood in light of that country's recent past. In 1964 a military dictatorship was established that shaped the country's political, social, and economic systems for over two decades. Brazil's political system under military rule was characterized by repressive measures intended to preserve order and discourage expressions of discontent (Diversi, Moraes, \& Morelli, 1999). Of particular relevance to the situation of impoverished youth, the Código 
de Menores (Minors' Code) was enacted in 1968 as a means of controlling and punishing individuals under 18 years old. Children and adolescents were subject to intimidation and violence and could be incarcerated in closed reformatories for indefinite periods for a range of infractions ranging from vagrancy to theft and violence. During the period of military rule, the abuse of children and adolescents became institutionalized and street youth were the frequent targets of abuse and even murder. This legacy of violence continues to affect the daily life of youngsters in many cities, despite dramatic changes in the political situation after the restoration of civilian rule in 1985.

Since that time, concerted efforts were made to improve the condition of children and adolescents. In 1990, the Estatuto da Criança e do Adolescente or ECA (Statute for Children and Adolescents) replaced the Minors' Code. The ECA guarantees children and adolescents certain basic rights including the right to health, respect, freedom, dignity, family and community support, education, culture, leisure, and job training. It also protects children against abuse and exploitation of all kinds. On paper, the ECA is a model document for preserving the rights of children, and it is consistent with the UNCRC. However, a number of factors have blocked full implementation of the statute's provisions. One major factor is that the economic situation in Brazil has fluctuated since the restoration of civilian rule, and although the economy is improving, investments in social programs have not been substantial enough to bring about significant improvement in the street youth situation.

A second factor impeding implementation of the ECA is lack of an existing welfare system to deliver services. The Brazilian government never developed a social welfare system to help families and individuals who could not take care of themselves. Instead, non-governmental organizations and religious agencies formed the basis for the social welfare system (Diversi et al., 1999). Until recently, street youth relied on such institutions for food, clothing, medical care, access to showers and laundry facilities, and recreational facilities. It was not until passage of the ECA that the government became responsible for housing homeless children and adolescents, and the response of different communities has varied dramatically. Some state and municipal governments have developed and maintained programs to assist impoverished children and their families. For example, in some locations families can apply for scholarships so children are able to go to school rather than work to help feed their families. For adolescents, apprenticeship programs have been developed so that youth can earn a living while learning a trade and attending school. However, despite the development of such programs, in many parts of the country street youth are little better off than they were under military rule, and the situation is largely unchanged.

A number of researchers and practitioners have dedicated themselves to conducting research to understand and ultimately benefit the situation of homeless youth in Brazil. As co-founder of the Center for Psychological Studies on Street Children (CEP-RUA) at the Federal University of Rio Grande do Sul, Brazil, the authors attempt to integrate and apply basic knowledge from developmental and social psychology to improve the quality of life of at-risk populations. Several collaborative research projects are being conducted, including examinations of basic developmental processes among impoverished youth (Carlo \& Koller, 1998; Carlo, Koller, \& Eisenberg, 1998), gender differences in street youth adjustment (Raffaelli et al., 2000), and how youth experience the street (Raffaelli et al., 2001; Raffaelli \& Koller, 2005; Raffaelli, Koller, \& de Morais, 2007a; Raffaelli, Koller, Santos, \& Morais, 2007b). This extensive work with a research team and other international collaborators who also do intervention (e.g., Alves et al., 2001, 2002; Koller, 2008; Koller \& Lisboa, 2007; Sacco, Souza, $\&$ Koller, in press) provides a set of exemplars from which to draw in our analysis of ethical issues confronting researchers in street settings, working with sensitive participants and dealing with issues such as sexuality, drug use and violence. 


\section{Ethical Issues Encountered in Research with Homeless Youth}

To help readers get a sense for what researchers encounter when they go to "the streets," we begin with a narrative condensed from field notes kept by Raffaelli during her first field trip as a "street youth researcher" the year she received her Ph.D. As a Brazilian national, Raffaelli had lived in Brazil while growing up; however, this was her first close encounter with homeless youth in their own environment.

Field notes, 8/28/90. Visit to abandoned house where group of kids is living. I was accompanied by R. [from Brazilian collaborating institution] and A. [from U.S. collaborating institution]. R. is well known to the children and our visit was the result of a chance meeting between her and a teenage girl she knew. The girl, who was pregnant, had expressed a longing to eat roast chicken. So we purchased several pre-cooked chickens and made our way to the residential neighborhood where the kids were living in a half built house. The house had a roof and walls but no floors or windows, and the second floor had not been finished, so the kids lived in the two first floor rooms and an outdoor patio. It was a rainy, cold day and twelve kids were inside: sitting in the living room, playing on the exposed beams of the second floor, and cooking rice under the stairs. They were three teenage girls (S. aged 17, her sister L. aged 14, and C. aged about 15); S.'s baby, about 18 months old; five boys aged 12-18 (two of whom appeared to be developmentally delayed), and three small boys aged 8-10. (There were usually 20 or so kids in the house but several had been arrested the day before, C.'s brother had spent the night with a girlfriend, and S. and L.'s other sister was temporarily living with their mother. The girls periodically moved back home but left when their mother was drinking or the lack of money became too extreme.) Several dogs were also present. When we arrived, the kids gathered in the "living room," which was furnished with a single sofa. S. walked with me to the local bakery to buy rolls and soft drinks. When we got back to the house, R. and I opened the rolls (by hand - the police had taken the kids' knives during the raid) and made sandwiches, using a window ledge as our work area. Everyone watched us closely, including the dogs and the baby. The older kids laughed at the baby, telling him to blink - he was totally fixated on the food. I had an orange left from lunch and asked his mother if he could have it; she said yes and when I offered it to him he grabbed it with both hands and started sucking on it as hard as he could. I took it away and peeled it while he watched anxiously, reaching out and whimpering. C. held him in her lap and fed orange segments to him one at a time. Once the sandwiches were ready, the kids and visitors formed a circle at the prompting of R., who led us all through some prayers (Our Father, Hail Mary, and grace). Then R. and A. distributed the food and drink. Bones were tossed onto the floor for the dogs and even the baby got some bits of meat to suck on. After the first round of sandwiches, one of the boys asked if he could have seconds, and when R. said yes he looked into the box where the sandwiches were and the other kids began yelling that he would take the biggest piece, it wasn't fair, R. should distribute the food. So she did. Some of the kids ate their sandwiches immediately; others wrapped them up for later. The younger kids wandered out of the room. We sat on the sofa and talked. After a while L. left the room, returning with a glass bottle containing a liquid that R. later told me was paint thinner. L. poured the thinner onto scraps of rag each kid produced. The kids started inhaling the thinner before we could say anything, and the moment for intervening passed. As the fumes dissipated, L. initiated a game involving sign language and then the girls sang songs to amuse the younger children. Several of the boys played on the roof and on the exposed beams of the second floor. R. chatted with C. about her pregnancy, and found out that she had received no prenatal care to date. We also found out that C.'s birth was not registered (a prerequisite to obtaining legal identification papers) until this year, and the government ordered X-rays to determine her age because she did not know her date of birth. When the driver from the University arrived to pick us up, one of the boys on the roof called down to tell 
us that the van was here, and we got up and said goodbye. C. and L. accompanied us to the van and hugged us and we promised to come back. As we drove off, the kids all waved.

At the end of the notes, written up immediately after leaving the house, Raffaelli added the following note:

This was very depressing - kids are not dressed warmly enough for weather, baby obviously hungry, use of thinner, lack of comfort and possessions (except for dogs, who have names and kids who identify as their owner). The kids are all thin, their clothes are ragged, and they are not particularly clean. S.'s baby was alert and strong, but had scabies on his hands, was not wearing a diaper, and was very dirty. The house is also dirty. R. says it's no good giving them things - they can't wash clothes (water is hauled from gas station, they have no soap), good items are often exchanged for food or drugs, and stuff gets wrecked. The last time the police chased them out of the house they lived under a highway overpass for two weeks, and when they came back the furniture they left behind had been destroyed.

Although by no means typical of all street youths' experience at the present time, this vignette provide a basis for identifying a number of ethical (and pragmatic) issues that must be confronted when conducting research with street youth. How do researchers apply ethical standards that have been developed for "mainstream" populations to youth who are surviving in settings characterized by physical need, lack of adult supervision, drug use, and psychological neglect? Specific issues include the problem of obtaining informed consent, the difficulty of applying the concept of minimal risk, the use of incentives in exchange for research participation, the need to balance respect for privacy with concerns about a child's well-being, and issues about how data are reported and used. Each of these issues, and ways of addressing them we have explored in our research, is discussed below

Informed consent. According to standard legal and ethical guidelines, researchers must obtain consent from a parent or guardian for child and adolescent's research participation. However, even this most basic requirement poses challenges for researchers who study street youth.

Most street youth are not orphans in the true sense of the word. In studies conducted in different Brazilian cities, the proportion of homeless youth who have no living parents is around 5\% (see Raffaelli, 1997, for a review). At the same time, many street youth have tenuous family ties or have lost contact with their families. For example, in a recent study, Paludo and Koller (2004) claimed that they rarely found children who had completely lost contact with their family, even though the relationship with the family has been considered as a key feature for defining street children. The majority had unstable family ties, and there was a small group of children who were on their own on the streets and who had lost contact with their family. The fact that street youth have families but may not be in a regular contact with them creates a pragmatic problem for researchers that could potentially be overcome, although it is unclear whether parents who have little contact with their children are in fact best suited to consent to their child's research participation. However, when family relationships are strained or negative, the safety of the child also becomes a paramount concern. A major precipitant for leaving home is to escape violence and abuse. In a study of 66 homeless youngsters, the most common reasons given for leaving home were to escape conflict or abuse (Raffaelli et al., 2000). In these situations, seeking parental consent is unlikely to be a realistic option. In recognition of this reality, in Brazil parental consent is usually waived for studies involving street youth. This is consistent with Brazilian law, guidelines established by the Brazilian Federal Psychology Council (Conselho Federal de Psicologia, 2000, Resolution n. 016/2000).

Typically, when parents are unavailable, researchers must seek the consent of a guardian or other legally designated adult. Ideally, this adult is someone who knows the child and can make an informed judgment about what is best for him or her. For homeless children and adolescents, it is not always easy to identify such a caring adult. In Brazil, a child's parents or legal guardians are usually responsible for the child's well-being; when 
children are on the street, the Ministério Público (Public Ministry) is legally responsible for their well-being. Thus, researchers can comply with the law by obtaining consent from this agency, although the extent to which children's best interest is adequately represented by a state-appointed guardian can be questioned.

At the CEP-RUA, research proposals are reviewed by the University's ethics committee. In the case of homeless youth, consent may be also obtained from the Ministério Público, but in addition, to ensure that the best interests of the youth are represented, input is also sought from representatives of the institution where children are living (e.g., shelters). Finally, verbal assent is obtained from the children or adolescents themselves. In cases where children are living at home, parental consent and youth assent are sought. Youth assent is particularly important in cases where there is suspicion of child abuse, given that the caregiver is often the abuser and may not be acting in the best interests of the child. In these cases, the researcher has to take every precaution to guarantee that the child's rights are preserved during the research process. While recognizing the importance of obtaining youth assent, we feel that it is important to emphasize that like many children (Hurley, 1997), impoverished and homeless youth may lack the cognitive skills to understand the implications of participating in research. Therefore, extra attention should be taken to ensure that mechanisms are in place to protect research participants from potential negative consequences of research participation.

Minimal risk. One concept used to evaluate the risks involved in research is that of "minimal risk." In essence, researchers and ethics committees ask whether the physical or psychological risk of participating in a research project is acceptable, given the risks individuals typically encounter in daily life (Levine, 1991). If research participation poses no more risk than everyday life, then it is deemed to be acceptable.

We feel strongly that the minimal risk standard is totally inadequate for evaluating research with street youth, who typically encounter high levels of risk during their daily lives. For example, sizeable percentages of street youth say they go hungry and have difficulty finding a safe place to sleep (Campos et al., 1994; Raffaelli et al., 2000; Neiva-Silva et al., 2005). Furthermore, homeless youth are at heightened risk of violence and premature death when compared to youth who work on the street but live at home (Aptekar, 1994; Campos et al., 1994; Hecht, 1998; Koller, 2008; Raffaelli, 1999). Given the harsh reality of life on the street, the concept of minimal risk is not a useful way of evaluating the risks of research projects. By definition, virtually all social science and medical research would not put street youth at minimal harm as it is typically defined. Instead, researchers and ethics committees must consider the potential negative consequences of research participation given the reality of life on the street, and assess whether the research would pose an unacceptable level of risk for children and adolescents. They should also carefully consider the potential benefits of the research and make sure they outweigh the potential risks. Only those with extensive knowledge about street youth in general, and the local context in particular, should be considered competent to conduct a risk-benefit analysis of this kind.

Use of incentives. Another issue researchers must confront revolves around the use of incentives in the context of extreme deprivation. Because street youth typically have little in the way of material possessions, and many are deprived of affection and attention, they may find even apparently minor incentives to be highly motivating. Therefore, care must be taken that participants do not feel coerced to participate in research studies for any reason.

It is common practice for researchers to provide participants with some form of incentive, both to compensate them for their time and effort and to increase participation rates. However, using inducements with street children may be an ethical problem, because a youngster who is hungry or has limited income-generating opportunities may be unduly swayed by even a small incentive (Hutz \& Koller, 1999). At the same time, researchers who do not provide some form of incentive or reward may feel they are exploiting youth. One possible 
resolution of this dilemma is to consider different types of incentives and evaluate the extent to which they might unduly pressure the specific population of youth, given the larger context of their lives.

Incentives can take different forms. Material incentives are those most commonly used in research, such as money, food, or clothing. However, these are precisely the kinds of inducements that may pose undue pressure, given that most street youth possess very little. Other forms of incentives include tangible but non-material incentives (e.g., direct assistance such as medical care or legal assistance) and informational incentives such as providing specific information (e.g., regarding risk activities) or referrals to service sites. Moreover, although not typically thought of as an incentive, we have noted that street kids often find the opportunity to speak with a caring adult intrinsically rewarding (Hutz \& Koller, 1999). At the CEP-RUA, material incentives are not used in research with homeless youth, but researchers offer children information or referrals for social services after data collection is complete. Because such information is readily to youth from other sources, they are unlikely to feel pressured to participate in a particular research project.

Balancing respect for privacy with participant wellbeing. During the course of conducting a study of street youth, researchers will often be told about, or directly observe, behavior that is illegal or potentially harmful to the participant. This is true not only in research that asks about such behaviors directly but also in research on apparently unrelated topics. A simple example is stealing, which may be reported when youth are asked about incomegenerating or survival activities, or even when asked to describe a typical day in their lives. Similarly, observations of youth in natural settings may lead to the discovery that youth are involved in drug use or has a not well care pregnancy (as illustrated in the earlier vignette).

It is difficult for researchers to know what to do with this information for several reasons. The first is that in many countries there is no suitable authority for reporting potentially self-injurious behavior, or the filing of such a report may result in incarceration rather than treatment. A second reason is that interference may violate the research methods; for example, ethnographic or participant observation research involves being non-obtrusive and nonjudgmental. Finally, researchers may hesitate to report illegal or potentially dangerous behavior because such an action may jeopardize their relationship with the youth. This final reason is particularly salient for researchers who are working long-term with street youth and hope to use their research to improve conditions for youth.

There is no simple solution to this dilemma, but researchers should be aware that it will arise and decide in advance how to handle the situation. It is absolutely essential to be thoroughly familiar with the relevant laws, and to formulate a plan for dealing with specific situations. For example, youth who arrive for an interview high, or who want to use drugs during an interview, can be rescheduled for a later time or asked to wait until after the interview. The debriefing process can be used to address issues of risk behaviors that came to light during data collection. As described above, CEPRUA researchers provide youth with information and referrals. In a project about HIV/AIDS, all information gathered from and about children might be treated as confidential; no reports will be sent to authorities. However, field researchers will provide all participants with referrals to medical clinics and open houses or shelters, which provide a variety of free services (e.g., showers, food, recreational programs). The clinic will provide medical care and referrals as necessary. Moreover, since descriptive information has being collected to develop prevention materials, eventually all children were offered the opportunity to participate in the intervention (Neiva-Silva et al., 2005).

Use and abuse of data. A final issue is what happens to research findings after they have been reported. Although this is largely outside an individual researcher's control, this issue is worth considering when studies are being designed and written up, because once findings have been published they may take on a life of their own and be used for purposes the researcher did not anticipate. Research findings may be taken out of context and 
used for other purposes (e.g., to shape policy decisions; Hutz \& Koller, 1999).

Because of the challenges inherent in conducting research with street youth, studies typically involve small opportunity samples and are conducted in only one location. As a result, it is extremely important that studies be replicated before findings are accepted as representing all street youth. Moreover, there are wide differences in conditions both across and within countries, so care should be taken when attempting to generalize from specific studies. Until studies are replicated in multiple samples and clear patterns are identified, broad conclusions should be avoided, and general recommendations should not be made. By restraining the conclusions they draw, and pointing out the limitations of their research, scholars can minimize the possibility that their findings will be misinterpreted or overstated by others.

\section{Conclusion}

Large segments of the world's population lives in conditions of poverty. Researchers, who become involved in research with impoverished populations in their own country, or across national boundaries, are likely to find themselves dealing with issues they have not been prepared to address. There is considerable literature addressing the logistical difficulties of conducting research with hidden or impoverished populations (e.g., Baker, PanterBrick, \& Todd, 1996; Gunther, 1992; Heckathorn, Robert, \& Sergeyev, 2001; Lisboa, Habigzang, \& Koller, 2008; Muhib et al., 2001). Far less has been published on the ethical aspects of research with disenfranchised populations of youth, especially related to sexuality, drug use and violence. In this paper, we have attempted to outline some of the challenges involved in conducting research with homeless and impoverished children and adolescents. Drawing on our experiences in Brazil, we identified some of the implications of conducting research with street youth and offered possible solutions to ethical dilemmas encountered by researchers. Developmental researchers are bound by a set of international and national laws and guidelines regarding ethical treatment of children and adolescents in research studies. However, the usual standards fail to take into account the unique situation of street youth, making it necessary for researchers to articulate their own standards. We hope that the ideas presented in this paper provide a basis for further dialogue on ethical considerations in street youth research. Similarly, Fontes (1998) suggested that ethical principles do not adequately address the moral issues that arise in conducting inquiry into many sensitive areas, including crosscultural and family violence research. Even with the best of guidelines and human subjects review boards and consultants, researchers ultimately face ethical issues alone with their consciences. Many ethical decisions will be based on "the amount of overnight tossing-and-turning that a researcher can tolerate" (p. 53).

\section{References}

Alves, P. B., Koller, S. H., Silva, M., Santos, C., Silva, A., Reppold, C., \& Prade, L. (2001). Brinquedo, trabalho, espaço e companhia de atividades lúdicas [Play, work, setting and companions during leisure activities]. Psico, 32, 47-71.

Alves, P. B., Koller, S. H., Silva, M., Santos, C., Silva, A., Reppold, C., \& Prade, L. (2002). Atividades cotidianas de crianças em situação de rua [Daily activities of children in street situations]. Psicologia: Teoria e Pesquisa, 18, 135-157.

Aptekar, L. (1994). Street children in the developing world: A review of their condition. Cross-Cultural Research, 28(3), 195-224.

Baker, R., Panter-Brick, C., \& Todd, A. (1996). Methods used in research with street children in Nepal. Childhood: A Global Journal of Child Research, 3, 171-194.

Campos, R., Raffaelli, M., Ude, W., Greco, M., Ruff, A., Rolf, J., Greco, D. (1994). Social networks and daily activities of street youth in Belo Horizonte, Brazil. Child Development, 65, 319-330.

Carlo, G., \& Koller, S. (1998). Desenvolvimento moral pro-social em criancas e adolescentes: Conceitos, metodologias, e Pesquisas no Brasil [Prosocial development in children and adolescents: Concepts, 
methodologies, and research in Brazil]. Psicologia: Teoria e Pesquisa, 14, 161-172.

Carlo, G., Koller, S., \& Eisenberg, N. (1998). Prosocial moral reasoning in institutionalized delinquent, orphaned, and noninstitutionalized Brazilian adolescents. Journal of Adolescent Research, 13, 363-376.

Carvalho de, F. T., Neiva-Silva, L., Ramos, M. C., Evans, J., Koller, S. H., Piccinini, C., Page-Shafer, K. (2006). Sexual and drug use risk behaviors among children and youth in street circumstances in Porto Alegre, Brazil. AIDS and Behavior, 32, 57-66.

Conselho Federal de Psicologia. (2000). Resolução para pesquisa com seres humanos [Resolution for research with human subjects]. Resolução 016/2000, Brasília.

Diversi, M., Moraes, N., \& Morelli, M. (1999). Daily reality on the streets of Campinas, Brazil. In M. Raffaelli, \& R. Larson (Eds.), Homeless and working youth around the world: Exploring developmental issues (pp. 19-34). San Franciso: Jossey-Bass.

Fontes, L. A. (1998). Ethics in family violence research: Cross-cultural issues. Family Relations, 47, 53-61.

Gunther, H. (1992). Interviewing street children in a Brazilian city. Journal of Social Psychology, 132, 359-367.

Heckathorn, D. D., Robert, S. B., \& Sergeyev, B. (2001). A methodology for reducing respondent duplication and impersonation in samples of hidden populations. Journal of Drug Issues, 31, 543-564.

Hecht, T. (1998). At home in the street: Street children of Northeast Brazil. New York: Cambridge University Press.

Hurley, J. C. (1997, April). Children's capacity to give truly informed assent for research participation and their understanding of debriefing. Poster presented at the Society for Research in Child Development Biennial Meeting, Washington, D.C., EE.UU.

Hutz, C. S., \& Koller, S. H. (1999). Methodological and ethical issues in research with street children. In M. Raffaelli \& R. Larson (Eds.), Homeless and working youth around the world: Exploring developmental issues (pp. 59-70). San Franciso: Jossey-Bass.

Koller, S. H. (2008). Ethics in research with human beings: Some issues about Psychology. Ciência Ë Saúde Coletiva, 13, 399-406. Retrieved in December 31, 2009, from http://www.scielo. br/scielo.php?script $=$ sci_arttext\&pid $=S 1413$. $81232008000200015 \& \operatorname{lng}=\mathrm{en} \& \mathrm{nrm}=\mathrm{iso}$

Koller, S. H., \& Lisboa, C. S. de M. (2007). Brazilian approaches to understanding and building resilience in at-risk populations. Child and Adolescent Psychiatric Clinics of North America, 16, 341-356.

Koller, S. H., \& Raffaelli, M. (2001, November). Street children's rights and well-being: Psychological, behavioral, and policy concerns. International Society for the Study of Behavioural Development (ISSBD) Newsletter, 2, 2-3.

Lisboa, C., Habigzang, L. F., \& Koller, S. H. (2008). Ética na pesquisa com temas delicados: Estudos em psicologia com crianças e adolescentes vitimas de violência doméstica [Ethical in research with sensitive issues: Psychology studies with domestic violence]. In I. Guerriero, M. L. S. Schmidt, \& F. Zicker (Eds.), Ética nas pesquisas em_ciências humanas e sociais na saúde. São Paulo: Hucitec. Retrieved on December 31, 2009, from http://www. abant.org.br/conteudo/livros/pesquisa.pdf

Levine, R. J. (1991). Respect for children as research subjects. In M. Lewis (Ed.), Child and adolescent psychiatry: A comprehensive textbook. Baltimore, MD: Williams \& Wilkins.

Lusk, M. W. (1992). Street children of Rio de Janeiro. International Social Work, 35, 293-305.

Ministério da Saúde. (1996). Informe Epidemiológico do SUS. Resolução n. 196/96, Suplemento 3, Ano V, n. 2. Brasília: Fundação Nacional de Saúde.

Muhib, F. B., Lin, L. S., Stueve, A., Miller, R. L., Ford, W. L., Johnson, U. D., \& Smith, P. J. (2001). A venue-based method for sampling hard-to-reach populations. Public Health Reports, 116, 216-222.

Neiva-Silva, L., \& Koller, S. (2002). A rua como contexto de desenvolvimento [The street as a developmental context]. In E. Lordelo, A. Carvalho, \& S. Koller (Eds.), Infância brasileira e contextos de desenvolvimento [Brazilian childhood and development contexts] (Vol. 1, pp. 205-230). São Paulo: Casa do Psicólogo.

Neiva-Silva, L., Lisboa, C.S.M., \& Koller, S. (2005). Bioética na pesquisa com crianças e adolescentes em situação de risco: Dilemas sobre o consentimento e a confidencialidade. DST [Bioethics in 
the research with at risk children and adolescents: Dilemmas on the consent and the confidentiality]. Jornal Brasileiro de Doenças Sexualmente Transmissiveis, 17(3), 201-206.

Paludo, S., \& Koller, S. (2004). Inserção ecológica no contexto da rua. In S. H. Koller (Ed.), Ecologia do desenvolvimento humano: Pesquisa e intervenção no Brasil (pp. 219-244). Porto Alegre: Casa do Psicólogo.

Raffaelli, M. (1997). Family situation of street youth in Latin America: A cross-national review. International Social Work, 40(1), 89-100.

Raffaelli, M. (1999). Street youth in Latin America: A developmental review. Interamerican Journal of Psychology, 33 (2), 7-28.

Raffaelli, M. \& Koller, S. H. (2005). Future expectations of Brazilian street youth. Journal of Adolescence, 28(2), 249-262.

Raffaelli, M., Koller, S. H., Bandeira, D., Reppold, C., Kuschick, M., \& Dani, D. (2000). How do street youth experience "the street"? Childhood: A Global Journal of Child Research, 8, 396-415.
Raffaelli, M., Koller, S. H., \& de Morais, N. A. (2007a). Assessing the development of Brazilian street youth. Vulnerable Children and Youth Studies, 2, 154-164.

Raffaelli, M., Koller, S., Reppold, C., Kuschick, M., Krum, F., Bandeira, D., \& Simões, C. (2001). Gender differences in Brazilian street youth's family circumstances and experiences on the street. Child Abuse $\mathcal{E}$ Neglect, 24, 1431-1441.

Raffaelli, M., Koller, S. H., Santos, E. C., \& de Morais, N. A. (2007b). Developmental risks and psychosocial adjustment among low income Brazilian youth. Development and Psychopathology, 19, 565-584.

Sacco, A. M., Souza, A. P., \& Koller, S. H. (in press). Child and adolescent rights in Brazil. The International Journal of Children's Rights.

Yick, A. G. (2007). Role of culture and context: Ethical issues in research with Asian Americans and immigrants in intimate violence. Journal of Family Violence, 22, 277-285. 
